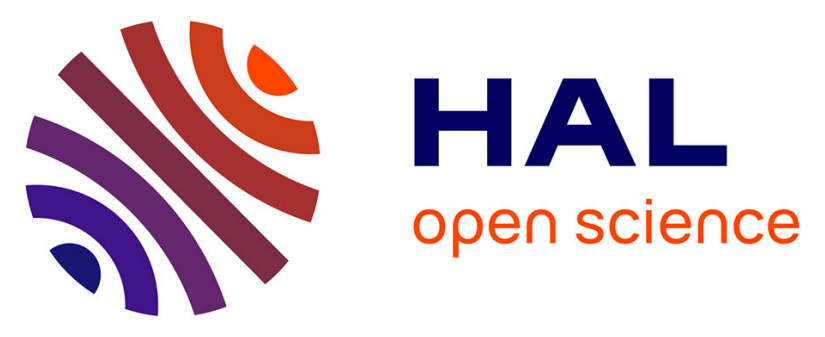

\title{
Is -5083del19, identified in breast cancer patients of Sicilian origin, a Calabrian founder mutation?
}

\author{
Antonio Russo, Valentina Calò, Loredana Bruno, Valentina Schirò, Valentina \\ Agnese, Sandra Cascio, Elena Foddai, Daniele Fanale, Sergio Rizzo, Francesca \\ Gaudio, et al.
}

\section{To cite this version:}

Antonio Russo, Valentina Calò, Loredana Bruno, Valentina Schirò, Valentina Agnese, et al.. Is 5083del19, identified in breast cancer patients of Sicilian origin, a Calabrian founder mutation?. Breast Cancer Research and Treatment, 2008, 113 (1), pp.67-70. 10.1007/s10549-008-9906-7 . hal-00478303

\section{HAL Id: hal-00478303 https://hal.science/hal-00478303}

Submitted on 30 Apr 2010

HAL is a multi-disciplinary open access archive for the deposit and dissemination of scientific research documents, whether they are published or not. The documents may come from teaching and research institutions in France or abroad, or from public or private research centers.
L'archive ouverte pluridisciplinaire HAL, est destinée au dépôt et à la diffusion de documents scientifiques de niveau recherche, publiés ou non, émanant des établissements d'enseignement et de recherche français ou étrangers, des laboratoires publics ou privés. 


\title{
Is $B R C A 1-5083 d e l 19$, identified in breast cancer patients of Sicilian origin, a Calabrian founder mutation?
}

\author{
Antonio Russo $\cdot$ Valentina Calò $\cdot$ Loredana Bruno $\cdot$ Valentina Schirò $\cdot$ \\ Valentina Agnese $\cdot$ Sandra Cascio $\cdot$ Elena Foddai $\cdot$ Daniele Fanale \\ Sergio Rizzo · Francesca Di Gaudio · Eliana Gulotta · Eva Surmacz • \\ Gaetana Di Fede · Viviana Bazan
}

Received: 10 October 2007 / Accepted: 15 January 2008/Published online: 29 January 2008

(C) Springer Science+Business Media, LLC. 2008

\begin{abstract}
Various studies have been published in Italy regarding the different $B R C A 1$ mutations, but only the BRCA1-5083del19 mutation is recurrent and specific to individuals of Italian descent with a founder effect on the Calabrian population. In our previous study, BRCAl5083del19 mutation carriers were found in four index cases of 106 Sicilian patients selected for familial and/or hereditary breast/ovarian cancers. The high frequency rate of this mutation identified in the Sicilian population led us to perform haplotype analysis in all family carriers. Five highly polymorphic microsatellite markers were used (D17S1320, D17S932, D17S1323, D17S1326, D17S1325) to establish whether or not all these families had a common ancestor. This analysis showed that all mutation carriers of
\end{abstract}

Antonio Russo and Valentina Calò have contributed equally to this work.

\footnotetext{
A. Russo $(\bowtie) \cdot$ V. Calò · L. Bruno · V. Schirò · V. Agnese ·

S. Cascio - E. Foddai - D. Fanale - S. Rizzo - G. Di Fede .

V. Bazan

Department of Oncology, Section of Medical Oncology, Regional Reference Center for the Biomolecular

Characterization and Genetic Screening of Hereditary Tumors, Università di Palermo, Via del Vespro 127, 90127 Palermo, Italy

e-mail: lab-oncobiologia@usa.net

F. Di Gaudio

Department of Medical Biotechnologies and Legal Medicine, Università di Palermo, Palermo, Italy

E. Gulotta

Department of GENURTO, Università di Palermo,

Palermo, Italy

E. Surmacz

Sbarro Institute for Cancer Research and Molecular Medicine, College of Science and Technology, Temple University, Philadelphia, USA
}

these families had a common allele. None of the noncarriers of the mutation or of the 50 healthy Sicilian controls showed this haplotype. This allelotype analysis highlighted the presence of a common allele (ancestor), thus suggesting the presence of a founder effect in the Sicilian population. Our results are in contrast with other studies but only the allelotype analysis of all the BRCAl5083del19 mutation carriers of two neighboring regions of the south of Italy (Calabria and Sicily) will make it possible to identify the real ancestor of this mutation.

Keywords BRCAl gene - Founder mutation · Haplotype analysis · Hereditary breast and ovarian cancer . Sicilian patients

\section{Introduction}

From 5-10\% of breast and ovarian cancers are hereditary; most of them can be attributed to mutations occurring in genes located in various chromosomes. BRCA1 and BRCA2 are known as susceptibility genes and appear to be involved in $30-45 \%$ of the cases which map in chromosomes $17 \mathrm{q} 21$ and 13q12-13 respectively [1-3]. The frequency and type of mutations in these genes vary according to the geographical area and ethnic group involved. Many such alterations may often be recurrent and have been identified in isolated populations as the results of a founder effect.

Founder mutations in BRCAI and BRCA2 genes have been described in several western European countries, but the most evident and restricted forms are those observed in the Icelandic and Ashkenazi Jewish populations [4-6].

BRCA1-185delAG is present in 1\% of the Ashkenazi Jews and in $20 \%$ of Ashkenazi women affected by breast cancer before the age of 42 years [7]. A further BRCAl founder 
mutation (5832insC) is found in $0.11 \%$ of the general population [8]. This mutation is frequently present in Jews and has moreover been identified in Poland, Lithuania, Hungary, Russia and in a large number of European countries [9-14]. The haplotype analysis of the mutation carriers show that such subjects have a common ancestor.

In Italy, different studies have been published regarding the different BRCAl mutations, but only the BRCAl5083del19 mutation is recurrent and specific to individuals of Italian descent.

Baudi et al. described this mutation as a founder mutation specific to the Italian population, but all the patients selected for their family history and as carriers of the mutation were of Calabrian origin. The haplotype analysis in these families shows that they have a common allele [15].

In a Canadian study involving 116 women with primary breast or ovarian cancer who had at least one Italian ancestor, the presence of BRCA1-5083del19 was observed in 5 families, only 3 of which quite certainly of Calabrian origin [16].

A knowledge of the nature and frequency of populationspecific mutations in susceptibility genes is an important step towards the development of a valid diagnostic approach to DNA analysis in particular ethnic groups [17].

In our study BRCA1-5083del19 mutation was found in $4 \%$ of 106 patients selected for familial and/or hereditary breast/ovarian cancers and all families confirmed their Sicilian origin [18].

The high frequency rate of this mutation found in the Sicilian population analyzed led us to perform haplotype analysis with five highly polymorphic microsatellite markers to establish whether or not all these families had a common ancestor.

\section{Patients and methods}

\section{Patients}

Four unrelated families with hereditary/familial breast and ovarian cancer were recruited after interview at the "Regional Reference Center for the Characterization and Genetic Screening of Hereditary Tumors" at the University of Palermo. All members declared that they originated from the Southern Italian region of Sicily.

Blood samples were obtained from four affected probands and from unaffected family members after obtaining written informed consent. All relatives underwent genetic counseling, conducted by an oncologist, a geneticist and a psychologist and were asked to provide information regarding their personal and familial history so that we were able to evaluate risk assessment and their genealogical tree. The latter was updated every year and investigated for at least three generations in order to identify patients with breast/ovarian cancer or other types of tumors and to evaluate the presence within the family of neoplasias related to BRCAl-associated tumors. All cancer diagnoses were confirmed by the pathologist's reports.

Twelve members of four families were enrolled for the study. Blood samples obtained from 50 healthy Sicilians served as controls; informed consent was obtained from all subjects before the collection of samples. All the material regarding each individual case (a personal data chart, interviews, blood samples) was filed under an individual personal code in order to respect the patient's privacy.

\section{Mutation detection}

Genomic DNA was extracted from whole peripheral blood according to the instructions contained in the QIAamp Blood Kit (Qiagen, Hilden, Germany). Direct sequencing of the PCR product of exon 16 of the BRCAl gene was performed using a BigDye Terminator v3.1 and then sequencing by ABI PRISM 3100 Avant Genetic Analyzer (Applied Biosystems, Foster City, CA) as described previously [18]. Each genetic variant was confirmed by direct sequencing analysis on two independent blood samples.

\section{Haplotype analysis}

The BRCAl haplotype was analyzed by using 5 microsatellite repeat markers located on chromosome $17 \mathrm{q}$ within or near BRCA1. From centromere to telomere, the order reported in the NCBI Data Base (http://www.ncbi.nlm. nih.gov) is as follows: D17S1320, D17S932, D17S1323, D17S1326, D17S1325 [19]. Primer sequences to amplify these markers retrieved on-line from the NCBI Data Base. Standard PCR protocol were used. The amplified products were visualized by microsatellite analysis with an automated apparatus (ABI Prism 3100 Avant, Applied Biosystems, USA).

The microsatellite repeat markers have been chosen so that two of them, D17S932 and D17S1323, are in inside the gene $B R C A 1$, the first in intron 12 and the other in intron 19.

The locus D17S1320 is at $500 \mathrm{~kb}$ upstream from the gene, while the other two D17S1326 and D17S1325 are downstream, and are at $195 \mathrm{~kb}$ and $400 \mathrm{~kb}$ from D17S1323 respectively.

\section{Results}

Of four 5083del19 mutation carriers probands $(5 \mathrm{Si}, 13 \mathrm{Si}$, $45 \mathrm{Si}, 55 \mathrm{Si}$ ), three had a strong family history. Only 
proband 45Si had been affected by early-onset breast cancer (at age 39), but no other member of her family had been affected by a tumor; furthermore, no other family member consented to be interviewed and undergo oncogenetic counseling. Twelve members of the four families were thus recruited during genetic counseling.

The proband of the 5Si family was a multiparous nonAshkenazi woman with bilateral breast cancer $(43,47)$. A maternal aunt who had developed breast cancer at age 50 and died at the age of 60 . Both her brother and her daughter were healthy carriers of the BRCA1-5083del19 mutation.

The 13Si index-case was a multiparous non-Ashkenazi woman with bilateral breast cancer developing at ages 70 and 93. Two of her daughters had developed ovarian cancer (46 and 50) and one of her granddaughters had developed breast cancer at 32 age; only one other daughter decided to undergo genetic testing and was found to be a healthy mutation carrier.

The proband of the 55Si family was a multiparous nonAshkenazi woman with bilateral breast cancer $(42,70)$. Both her sons were healthy carriers, and her daughter, who had died of breast cancer at the age of 32, must certainly have been a carrier, since both her children were found to be healthy carriers. This woman had a sister with breast cancer at 50 age and a nephew with ovarian cancer at 45 age.

Twelve members of four families were typed with five microsatellite markers within or flanking the BRCAl gene. All the cases with the BRCA1-5083del19 mutation shared a common haplotype at loci D17S1320, D17S932, D17S1323, D17S1326, D17S1325, respectively. The genealogical tree of the 5Si family shows the segregation of the allele associated with the BRCA1-5083del19 mutation (Fig. 1).

Haplotype analysis for non-carriers of the mutation showed that none of these and none of the 50 healthy Sicilian controls had this haplotype associated with the BRCA1-5083del19 mutation.

Allelotype analysis highlighted the presence of a common allele in the affected individuals and healthy carriers, therefore suggesting the presence of a founder effect in Sicilian families.

\section{Discussion}

The proportion of families at high-risk due to $B R C A l$ gene germline mutations varies widely among populations. In some groups a wide spectrum of different mutations are present, whereas in others specific mutations have been reported with high frequency as the result of a founder effect.

The comparison of haplotypes between families with the same mutation can distinguish whether high-frequency alleles derive from an older or more recent single

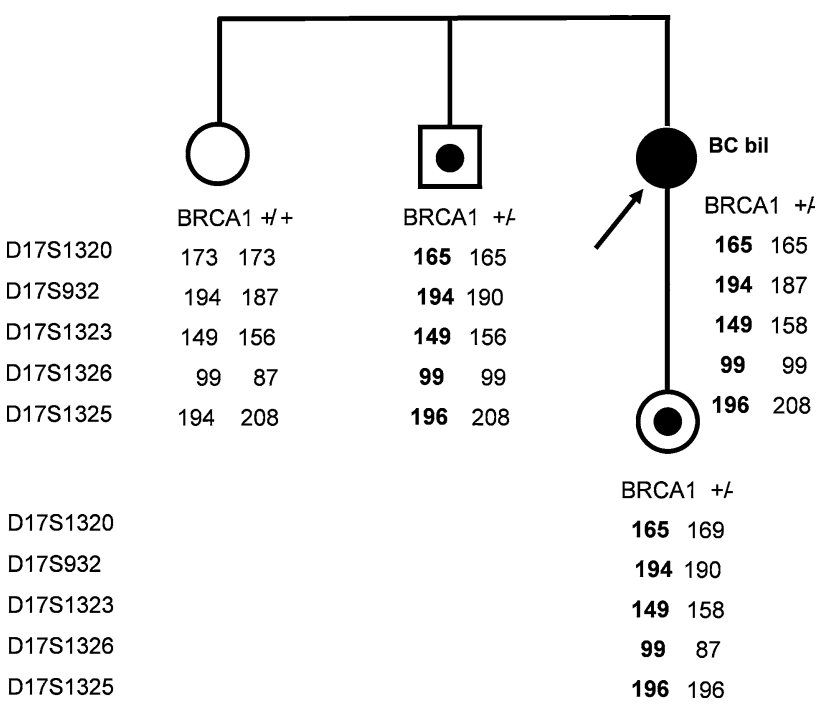

Fig. 1 Abbreviated pedigree of one of four Sicilian families that result BRCA1-5083del19 mutation carriers. The index case is indicated by an arrow. Each member show the result of haplotype analysis performed with five microsatellite markers

mutational event or whether they have arisen independently more than once.

The first example of BRCAl founder mutation in the Italian population was described by Baudi et al. in 2000 . All the families with BRCA1-5083del19 mutation originated from Calabria and haplotype analysis performed on the probands and on the healthy family carriers showed a common allele. This indicated a founder effect, in concordance with the genetic background of the Calabrian population, which is homogeneous and associated with negligible immigratory phenomena [15].

In 2004, the "Italian Consortium of Hereditary Breast and Ovarian Cancer" established that the prevalence of $B R C A 1 / 2$ mutations in 1758 Italian families was $23 \%$ and only a few of these mutations proved to be recurrent in particular geographical areas, among which BRCA15083del19, considered as the Calabrian founder mutation [20].

A North American study performed on 116 women of Italian origin with primary breast or ovarian cancer showed this mutation in 5 of the families involved, three of which of Calabrian origin [16].

These data highlighted that this is a founder mutation most probably originating in Calabria.

In 2006, we published the first study regarding BRCA1 gene molecular screening in Sicilian patients affected by breast and/or ovarian tumors and identified 4 families carrying this mutation. Three index cases had bilateral breast cancer and within their families there were members affected by both breast and ovarian cancers, as already 
found in the other Italian families who were BRCAl5083del19 mutation carriers [18].

Our results were not included in those of the Italian Consortium, since we studied the Sicilian population only subsequent to its publication. All our probands declared that they were of Sicilian origin. Allelotype analysis with 5 microsatellite repeat markers within or near BRCA1 highlighted the presence of a common allele in the four affected individuals and eight healthy carriers, therefore suggesting the presence of a common ancestor.

Several other recurrent mutations have been identified in other limited areas of Italy, but only genetic screening performed on a larger number of cases within the various regions of the country will make it possible to reach more definite conclusions regarding the presence of this founder effect.

The identification of the ethnic group of families undergoing genetic counseling enables the geneticist and oncologist to make more specific choices, helping to simplify the clinical approach to genetic testing performed on members of high-risk families.

In conclusion, only a haplotype analysis using the same microsatellite repeat markers in all BRCA1-5083del19 mutation carriers of Italian families will make it possible to understand if all these families originating from two neighboring regions of the south of Italy (Calabria and Sicily) have a common ancestor.

\section{References}

1. Miki Y, Swensen J, Shattuck-Eidens D et al (1994) A strong candidate for the breast and ovarian cancer susceptibility gene BRCA1. Science 266:66-71

2. Ford D, Easton DF, Stratton M, Breast Cancer linkage Consortium et al (1998) Genetic heterogenicity and penetrance analysis of the BRCA1 and BRCA2 genes in breast cancer families. Am J Hum Genet 62:676-689

3. Pharoah PD, Antoniou A, Bobrow M et al (2002) Polygenic susceptibility to breast cancer and implications for prevention. Nat Genet 31:33-36

4. Antoniou AC, Pharoah PD, Narod S et al (2005) Breast and ovarian cancer risks to carriers of the BRCA1 5382insC and
185delAG and BRCA2 6174delT mutations: a combined analysis of 22 population based studies. J Med Genet 42:602-603

5. Rudkin TM, Hamel N, Galvez M et al (2006) The frequent BRCA1 mutation 1135insA has multiple origins: a haplotype study in different populations. BMC Med Genet 7:15

6. Ferla R, Calo V, Cascio S et al (2007) Founder mutations in BRCA1 and BRCA2 genes. Ann Oncol 18(Supp 6):vi93-vi98

7. Struewing JP, Abeliovich D, Peretz T et al (1995) The carrier frequency of the BRCA1 185delAG mutation is approximately 1 percent in Ashkenazi Jewish individuals. Nat Genet 11:198-200

8. Roa BB, Boyd AA, Volcik K et al (1996) Ashkenazi Jewish population frequencies for common mutations in BRCAl and BRCA2. Nat Genet 14:185-187

9. Simard J, Tonin P, Durocher F et al (1994) Common origins of BRCA1 mutations in Canadian breast and ovarian cancer families. Nat Genet 8:392-398

10. Vehmanen P, Friedman LS, Eerola H et al (1997) Low proportion of BRCA1 and BRCA2 mutations in Finnish breast cancer families: evidence for additional susceptibility genes. Hum Mol Genet 6:2309-2315

11. Johansson O, Ostermeyer EA, Hakansson S et al (1996) Founding BRCA1 mutations in hereditary breast and ovarian cancer in Southern Sweden. Am J Hum Genet 58:441-450

12. Hakansson O, Johansson U, Sellberg G et al (1997) Moderate frequency of BRCA1 and BRCA2 germ-line mutations in Scandinavian familial breast cancer. Am J Hum Genet 60:1068-1078

13. Peelen T, van der Vliet M, Petrij-Bosch A et al (1997) A high proportion of novel mutations in BRCAl with strong founder effects among Dutch and Belgian hereditary breast and ovarian cancer families. Am J Hum Genet 60:1041-1049

14. Thorlacius S, Olafsdottir G, Tryggvadottir L et al (1996) A single BRCA2 mutation in male and female breast cancer families from Iceland with varied cancer phenotypes. Nat Genet 13:117-119

15. Baudi F, Quaresima B, Grandinetti C et al (2001) Evidence of a founder mutation of BRCAl gene in a highly homogeneous population from southern Italy with breast/ovarian cancer. Hum Mutat 18:163-164

16. Nedelcu R, Liede A, Aube $\mathrm{J}$ et al (2002) BRCA mutations in Italian breast/ovarian cancer Families. Eur J Hum Genet 10:150-152

17. Ottini L, D'Amico C, Noviello C et al (2000) BRCA1 and BRCA2 mutations in central and southern Italian patients. Breast Cancer Res 2:307-310

18. Russo A, Calo' V, Agnese V et al (2006) BRCAl genetic testing in 106 breast and ovarian cancer families from southern Italy (Sicily): a mutation analyses. Breast Cancer Res Treat (2007 Jan 13)

19. National center for biotechnology information (NCBI) Data Base. Retrived online (http://www.ncbi.nlm.nih.gov)

20. Cipollini G, Tommasi S, Paradiso A et al (2004) Genetic alterations in hereditary breast cancer. Ann Oncol 15(Supp 1):i7-i13 